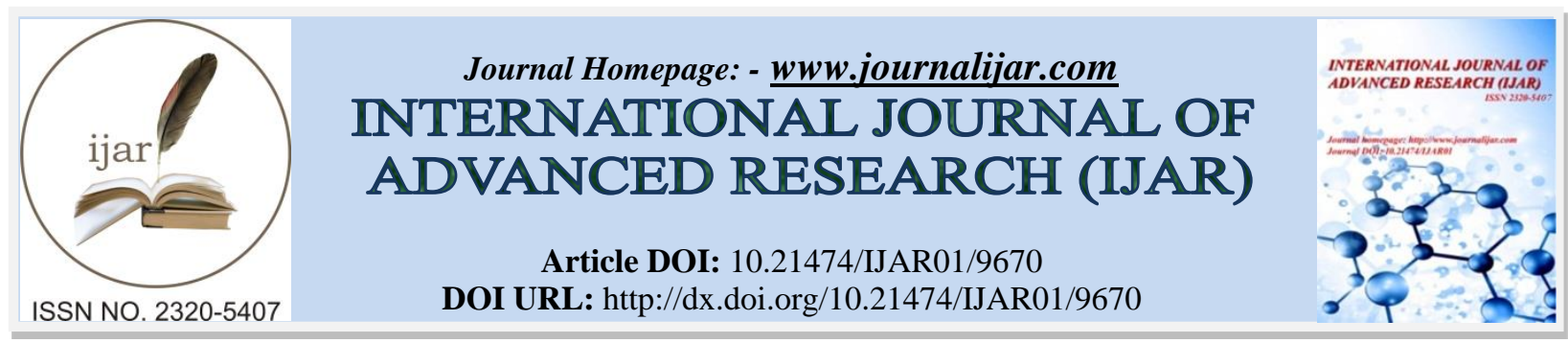

RESEARCH ARTICLE

\title{
HEALTH SYSTEM RESPONSIVENESS AND ITS CORRELATES AT OUTPATIENT DEPARTMENT SERVICE IN DISTRICT GENERAL HOSPITAL, KALUTARA
}

\section{${ }^{1}$ Kasunee Chamila Kalubowila, ${ }^{2}$ Dinesha Perera, ${ }^{2}$ Champika Alahapperuma ${ }^{3}$ Inoka Senathilaka, ${ }^{4}$ Ramani Devika Withana and ${ }^{5}$ Palitha Dharmabandhu Kapparage}

${ }^{1}$ Senior Registrar in Community Medicine, Anti-malaria campaign, Ministry of Health, Nutrition and Indigenous Medicine, ${ }^{2}$ Medical officer, District General Hospital, Kalutara, ${ }^{3}$ Medical officer, Base Hospital, Horana, ${ }^{4}$ Medical officer, National Hospital of Sri Lanka, ${ }^{5}$ Medical officer, Colombo South Teaching Hospital

\section{Manuscript Info}

Manuscript History

Received: 06 July 2019

Final Accepted: 08 August 2019

Published: September 2019

Keywords: Health system responsiveness, outpatient department, patient satisfaction

\section{Abstract}

Background: Patients desires on outpatient services at hospitals are varied, yet due to unexploring their needs resulting in patient dissatisfaction.

Objectives: To assess the health system responsiveness and its correlates at out-patient department in District General Hospital, Kalutara.

Methods: We conducted a cross-sectional descriptive study among 423 out-patients at District General Hospital, Kalutara in 2018, selected using a systematic sampling method. We included patients of age over 18 years, while excluded critically ill patients and the patients who repeatedly got selected for the study on their subsequent visits.We assessed the health system responsiveness under eight domains and collected data using an interviewer-administered questionnaire.

Results: Response rate was $93.6 \%(n=396)$. The majority consisted of females $(n=266,67.2 \%)$. Responsiveness varied according to the each domain: confidentiality (56.8\%), communication (56.1\%), dignity (55.3\%), quality of basic amenities (42.7\%) and social support during care $(41.4 \%)$. Further, most patients $(n=324,81.9 \%)$ didn't satisfy on waiting time at dispensary and total time spend for obtaining health care services $(n=351,88.6 \%)$. Females $(\mathrm{p}=0.01)$, elderly patients $(\mathrm{p}=0.000)$, being employed $(\mathrm{p}=0.000)$ and patients drew higher monthly income $(\mathrm{p}=0.000)$ were significantly less-satisfied with the overall services.

Conclusions: Most patients have higher responsiveness to overall services. However, areas such as choice of care provider need to be implemented and prompt attention need further improvement. Strengthening the infrastructure and introducing an appointment system are recommended.

Copy Right, IJAR, 2019. All rights reserved.

Corresponding Author: - Kasunee Chamila Kalubowila, Anti-malaria campaign, Ministry of Health, Nutrition and Indigenous Medicine 


\section{Introduction:-}

Health system comprises of organizations, institutions and resources that are devoted to producing health actions (WHO, 2018). It has been undergone various reforms very fast over the past years, thus nowadays it provides integrated and comprehensive curative, preventive, rehabilitative and promotive health services (WHO, 2000). Further, patients' views are being assumed more and more important nowadays, therefore, improving the performance among health staff and assessment of health system become very crucial (Jang et al., 2005).

World Health Report (2000) has emphasized three intrinsic goals of any healthcare delivery system such as improving health, fair financing and financial risk protection and responsiveness to assess the performance of health system. Accordingly, the degree to which the non-medical expectations of the people which is called 'responsiveness' are encountered and become much public debate and criticism these days, thus, the health system must pay attention to the factors affecting well-being of the patients besides mere medical needs (Valentine et al., 2003: Arokiasamy et al., 2006).

Health system responsiveness (HSR) is defined as 'how a health system has performed relative to non-medical aspects meeting or not meeting population's expectations of how it should be treated by providers of prevention and care of non-personnel services' (WHO, 2000). This concept was centred on two main domains initially such as 'respect for persons' and 'client orientation'. Further, these two domains were extended to eight domains such as prompt attention, dignity, communication, autonomy, confidentiality, basic amenities, choice of health care provider and social support which is included in the concept of HSR (WHO, 2001).

Sri Lanka has achieved many standards in health status and health care services (Ministry of Health, 2008). Despite the success in health outcomes, the Key Informant Survey (1999) on responsiveness highlighted that rating was low on quality of basic amenities, autonomy and dignity (WHO, 2000: Valentine et al, 2003). However, the rating for out-patient services was higher than that for inpatient services. Further, the ratings varied in different settings therefore, assessment of responsiveness in each healthcare institution to identify the poorly performing domains is crucial with the aim of rectifying those which could contribute to making a responsive and well-performing health care networking in the country.

District General Hospital (DGH), Kalutara serves as the main hospital in the district of Kalutara providing health care facilities to many outpatients and inward patients. The Out Patient Department (OPD) of the hospital caters to more than 10,000 patients per year. Thus, identifying the degree of HSR could be benefited to the health administrators to improve the performance at OPD which has not explored previously (Ministry of Health, Nutrition and Indigenous Medicine, 2018). Similarly, the distribution of responsiveness is also important that it implies sociodemographic and economic inequalities (Liabsuetrakul et al., 2012). Women, children and elderly people are at risk population and could be treated worse than the rest of the population (WHO, 2000). Further, it is identified, there are many factors related to both the health sector as well as the sociocultural context, which determine people's assessment on HSR (Mosadeghrad, 2014). These correlates play an important role in the assessment and could provide insight for policymakers and service providers to improve service provision. Therefore, identifying the vulnerable groups would be great use to the health care providers at the point of delivery of the services as it is primarily providing the information to improve the way in which the patients are treated. Further, the findings of this study have great value for the policymakers, programme managers and medical administrators at the district as well as the provincial and national levels.

\section{Methods:-}

This was a cross-sectional study conducted among outpatients over 18 years of age attending to DGH Kalutara in September 2018. Patients who repeatedly got selected for the study on their subsequent visits during the data collection period and critically ill patients were excluded from the study. The required sample size was calculated as 423 to detect an estimated proportion of responsiveness with services received of 50\%; $\mathrm{Z}$ value of 1.96 ; precision of 5\%; and non-response of 10\% (Lwanga and Lemeshow, 1991). Using a systematic sampling technique, eligible patients giving informed written consent were recruited for the study, while awaiting their turn for consultation and completed the data collection when they finished all services. An attempt was made to collect data with minimal disturbance to them. 
Data were collected using a pre-tested interviewer-administered questionnaire, which consisted of three sections: personal characteristics of the participants, general information on healthcare obtained at the OPD and questions related to HSR. The questionnaire was designed after a detailed literature survey considering the studies conducted in developed as well as developing countries. The judgmental validity was assessed by a panel of experts consisting of consultant community physicians and medical administrators.

Data analysis was carried out using Statistical Package for Social Sciences (SPSS) software version 23. Responses obtained for each question on responsiveness with the OPD services were presented as frequency distributions related to five point Likert's scale ranging from 'strongly disagree' to 'strongly agree'. For each domain of responsiveness and overall HSR, the patients were asked to rate in a scale of 'very poor' to 'very good' and presented as frequency distributions. Percentage of ranking of each domain was calculated and presented as percentages. The responses for 'very poor' and 'poor' were amalgamated and categorized as 'less satisfactory', 'good' and 'very good' were amalgamated and categorized as 'satisfactory' and 'neutral' presented as it is. Further, 'less satisfactory', 'neutral' and 'satisfactory' level of HSR were compared with the socio-demographic variables such as gender, age, the highest level of education, current employment status and monthly income using chi-square test and 0.05 considered as statistically significant. Ethics clearance was obtained from National Institute of Health Sciences, Kalutara prior to the data collection. Further, permission to conduct the study was obtained from the Director at DGH, Kalutara.

\section{Results:-}

Improvement of HSR needs comprehensive planning to increase attitudes of healthcare providers and system behaviour. Thus, findings of different patient group are needed to improve holistic management. Majority $(\mathrm{n}=207$, $52.3 \%$ ) reported 'good' or 'very good' total responsiveness related to eight domains in this study. The most of the patients included for the current study could be suffered from acute illnesses that could reflect as half of the patients $(\mathrm{n}=198,50.0 \%)$ self-referred and treatment received from less than one month duration, thus they could perceived good quality of care. Similarly, in a study conducted in Iran among patients diagnosed with diabetes mellitus (DM) attending to the OPD, 67\% $(\mathrm{n}=100)$ were classified as good for total responsiveness, which received higher responsiveness compared to our study (Sajjadi et al., 2015). However, the studies conducted in the South East Asian countries separately demonstrated the varying level of total responsiveness. Accordingly, a national populationbased cross-sectional study which was conducted in South Africa in 2008 among sample of 3,840 individuals aged 50 years or older reported the overall mean perceived responsiveness score for outpatient care as 69 and prompt attention showed the lowest score while quality, confidentiality, and dignity showed the highest degree of perceived responsiveness scores (Sajjadi et al., 2015). Consequently, other middle-income countries reported a lesser mean value such as China (53-55), India (52-51) and Malaysia (58-60) (Kowal et al., 2011). These different values merely not indicated the low figures in different countries, but also it could be due to study tools for assessment of responsiveness. Thus, these studies highlighted the importance of availability of a valid questionnaire to assess the responsiveness level at different settings within the country and comparison of each country.

HSR is a distinct, complex and not yet sufficiently explored concept (Siddiqi et al., 2009: Brinkerhoff \& Bossert, 2013: Cleary et al., 2013). Therefore identifying the level of its domains is very crucial in improvement of health system. Confidentiality, dignity and clear communication were rated as the three most important components of HSR in order to obtain higher satisfaction in the current study. Similarly, prompt attention, dignity and clear communication were rated as the three most important components of HSR in order to provide a high rate of performance in a study carried out in Thailand among 2822 immediate post-partum women (Liabsuetrakul et al., 2018). The lowest importance was rated as freedom of choice of health-care provider in the current study similar to the study conducted in South Africa, which rates high responsiveness for dignity, confidentiality, amenities, support, communication, waiting time and autonomy (Peltzer, 2009). In the study conducted in Iran among DM patients, the best (84\%) performing results were related to information confidentiality and autonomy (51\%). In addition, nearly $61 \%$ reported 'communication' as the most important domain of responsiveness and ranked in $4^{\text {th }}$ position (Sajjadi, et al., 2015). In contrast, the studies on mental health care in Germany showed that communication, autonomy, prompt attention, confidentiality, dignity, social support, amenities, choice of provider and continuity were important domains, respectively (Bramesfeld, 2007: Perera, 2011). Therefore, improvement of identified important components of HSR at OPD at DGH, Kalutara is support to improve service needs in Sri Lanka as a resource less developing country. 
Fifty percent $(n=198)$ of patients reported good satisfaction on time taken for registration in the OPD, however, $17.6 \%(n=50)$ satisfied on time to receive health care services after registration in the OPD. The studies on HSR at OPD in Sri Lanka are not available, but there are two studies conducted in Base Hospital (BH) Panadura recently and BH Homagama (Kalubowila et al., 2017: Koggalage et al., 2016). The study conducted at OPD in BH Panadura revealed poor satisfaction of less than $50 \%$ of the total score with the registration $(n=138,38.4 \%)$. It further highlighted the poor satisfaction on waiting time for consultation $(n=120,33.4 \%)$, and examination done by doctor $(\mathrm{n}=131,36.5 \%)$ (Kalubowila et al., 2017). Similarly, the waiting time reported as low in figures and presented as an important indicator in a study conducted in BH Homagama (Koggalage et al., 2016). Therefore, it is very important to streamline the electronic health recording system in OPD to reduce the waiting time, which should be addressed by medical administrators and policy makers in the country.

Less satisfaction was significantly associated with elderly age $(\mathrm{p}=0.000)$, female sex $(\mathrm{p}=0.01)$, being employed $(\mathrm{p}=0.000)$ and patients drew higher monthly income $(\mathrm{p}=0.000)$ in the current study. In contrast, a population-based survey of 2352 participants (1116 men and 1236 women) which was conducted in South Africa in 2003, showed overall patient non-responsiveness for the public out-patient service was $16.8 \%$ and $3.2 \%$ for private care. Further, this study did not find significant associations between socio-demographic variables (age, sex and education) and patient satisfaction (Peltzer, 2009). Therefore it is clear that at-risk population is different in different settings where the facts should be frequently assessed to improve the services.

\section{Conclusions and Recommendations:-}

Responsiveness of the most OPD patients was good based on their experiences related to communication, dignity and confidentiality. In contrast, it was poor for choice of care provider and prompt attention. Also, most patients didn't satisfy on waiting time at dispensary and total time spends for obtaining health care services at the OPD.

Authorities need to address the issue of waiting time by introducing an appointment system. The service delivery at the government sector should be attractive to the elderly and employed patients; therefore hospital administrators need to improve service delivery specially targeting these groups. The areas with dissatisfaction rates should be identified and discussed by the hospital management and relevant authorities to improve quality service.

\section{Author Declarations}

Conflicts of interests:

The authors declare that they have no competing interests.

\section{Ethics approval and consent to participate:}

Ethics clearance was obtained from the Ethics Review Committee from National Institute of Health Science, Kalutara, Sri Lanka. Written authorization was obtained from the Director, DGH, Kalutara and informed written consent from the participants.

\section{Funding: None}

\section{Acknowledgements:}

The authors would like to acknowledge the Director, staff and patients who provided the data at the OPD in DGH, Kalutara

\section{Author contribution:}

All authors were involved in conceptualizing and interpretation of data. The principal investigator was involved in data collection and drafting the manuscript. All authors revised it critically for intellectual content and gave final approval. 
Table 1:-Socio-demographic characteristics of the OPD patients

\begin{tabular}{|c|c|c|c|}
\hline Socio-demographic factors & Male, $\mathrm{n}=130(\%)$ & Female, $n=266(\%)$ & Total, $\mathrm{n}=396(\%)$ \\
\hline \multicolumn{4}{|l|}{ Age (years) } \\
\hline $18-40$ & $45(34.6)$ & $56(21.0)$ & $101(25.5)$ \\
\hline $41-60$ & $64(49.2)$ & $200(75.2)$ & $264(66.7)$ \\
\hline$>60$ & $21(16.2)$ & $10 \quad(3.8)$ & $31(7.8)$ \\
\hline \multicolumn{4}{|l|}{ Ethnicity } \\
\hline Sinhalese & $97(74.7)$ & $179(67.3)$ & $276(69.7)$ \\
\hline Tamil & $6(4.6)$ & $4(1.5)$ & $10(2.5)$ \\
\hline Muslim & $15(11.5)$ & $62(23.3)$ & $77(19.5)$ \\
\hline Other & $12(9.2)$ & $21(7.9)$ & $33(8.3)$ \\
\hline \multicolumn{4}{|l|}{ Current marital status } \\
\hline Unmarried & $40(30.7)$ & $89(33.5)$ & $129(32.6)$ \\
\hline Married & $82(63.1)$ & $165(62.0)$ & $247(62.4)$ \\
\hline Widowed/ Separated & $8(6.2)$ & $12(4.5)$ & $20 \quad(5.0)$ \\
\hline \multicolumn{4}{|l|}{ Highest educational level } \\
\hline Primary & $10(7.7)$ & $34(12.8)$ & $44(11.1)$ \\
\hline Secondary & $82(63.1)$ & $165(62.0)$ & $247(62.4)$ \\
\hline Passed G.C.E (O/L) examination & $30(23.0)$ & $35(13.2)$ & $65(16.4)$ \\
\hline Passed G.C.E. (A/L) or equivalent & $8 \quad(6.2)$ & $32(12.0)$ & $40(10.1)$ \\
\hline \multicolumn{4}{|l|}{ Current employment status } \\
\hline Unemployed & $54(41.5)$ & $135(50.7)$ & $189(47.7)$ \\
\hline Self-employed & $45(34.6)$ & $56(21.1)$ & $101(25.5)$ \\
\hline Other employment & $31(23.9)$ & $75(28.2)$ & $106(26.8)$ \\
\hline \multicolumn{4}{|l|}{ Monthly income } \\
\hline Less than Rs. 10,000 & $34(26.1)$ & $74(27.8)$ & $108(27.2)$ \\
\hline Rs. $10,001-25,000$ & $52(40.0)$ & $119(44.7)$ & $171(43.2)$ \\
\hline Rs. $25,001-40,000$ & $24(18.5)$ & $38(14.3)$ & $62(15.7)$ \\
\hline More than Rs. 40,000 & $20(15.4)$ & $35(13.2)$ & $55(13.9)$ \\
\hline
\end{tabular}

Table 2:-General information on health care obtained at the OPD

\begin{tabular}{lrr}
\hline Characteristics & $\mathbf{n = 3 9 6}$ & $\mathbf{\%}$ \\
\hline Distance from residence to hospital & & 24.4 \\
$<1 \mathrm{~km}$ & 97 & 21.5 \\
1 to $5 \mathrm{~km}$ & 85 & 18.7 \\
6 to $10 \mathrm{~km}$ & 74 & 16.2 \\
11 to $20 \mathrm{~km}$ & 64 & 19.2 \\
$>20 \mathrm{~km}$ & 76 & 24.0 \\
\hline Knowing of any health care provider in the hospital & & 76.0 \\
Yes & 301 & \\
No & & 9.1 \\
Referred person to the OPD & 36 & 11.4 \\
A staff member in the hospital & 45 & 26.0 \\
A staff member in another state hospital & 103 & 3.0 \\
A doctor in private medical institution & 12 & 50.0 \\
A patient attending to this hospital & 198 & 0.5 \\
Self-referral & 2 & \\
Other & & 39.8 \\
\hline Duration of receiving care from the OPD & 158 & 16.4 \\
< month & 65 & 23.2 \\
to 6 months & 92 & 3.0 \\
13 to 60 months & 12 & 17.4 \\
\hline$>60$ months & 69 & \\
\hline
\end{tabular}


Table 3:-HSR on health care services received according to the eight domains by patients at the OPD

\begin{tabular}{lrrrrr}
\hline HSR domain & Very poor & Poor & Fair & Good & Very good \\
\hline Dignity & $47(11.9)$ & $43(10.9)$ & $87(22.0)$ & $87(22.0)$ & $132(33.3)$ \\
Autonomy & $109(27.5)$ & $90(22.7)$ & $47(11.9)$ & $67(16.9)$ & $83(21.0)$ \\
Confidentiality & $35(8.8)$ & $21(5.3)$ & $115(29.0)$ & $178(44.9)$ & $47(11.9)$ \\
Communication & $64(16.2)$ & $62(15.7)$ & $48(12.1)$ & $124(31.3)$ & $98(24.7)$ \\
Prompt attention & $96(24.2)$ & $198(50.0)$ & $21(5.3)$ & $41(10.4)$ & $40(10.1)$ \\
Choice of care provider & $238(60.1)$ & $121(30.6)$ & $21(5.3)$ & $14(3.5)$ & $2(0.5)$ \\
Quality on basic amenities & $64(16.2)$ & $67(16.9)$ & $96(24.2)$ & $75(18.9)$ & $94(23.7)$ \\
Social support during care & $75(18.9)$ & $79(19.9)$ & $78(19.7)$ & $91(23.0)$ & $73(18.4)$ \\
\hline
\end{tabular}

Social support during care

Quality on basic amenities

Choice of care provider

Prompt attention

Communication

Confidentiality

Autonomy

Dignity

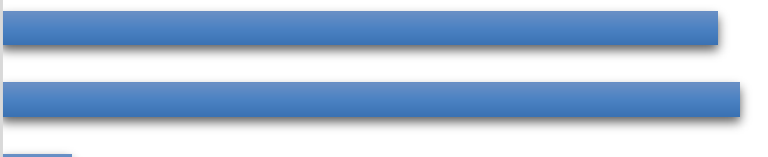

$41.4 \%$

$42.7 \%$

$4.0 \%$
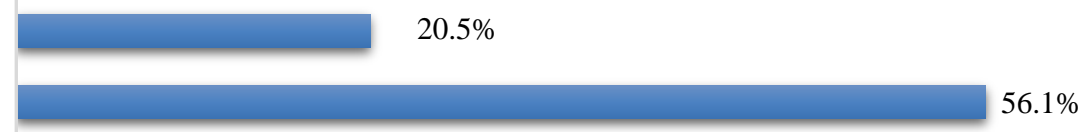

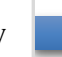

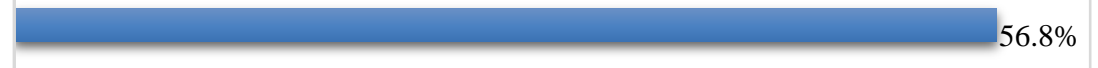

$37.9 \%$

Figure 1:-Percentage rating 'good' and 'very good' responsiveness in eight domains

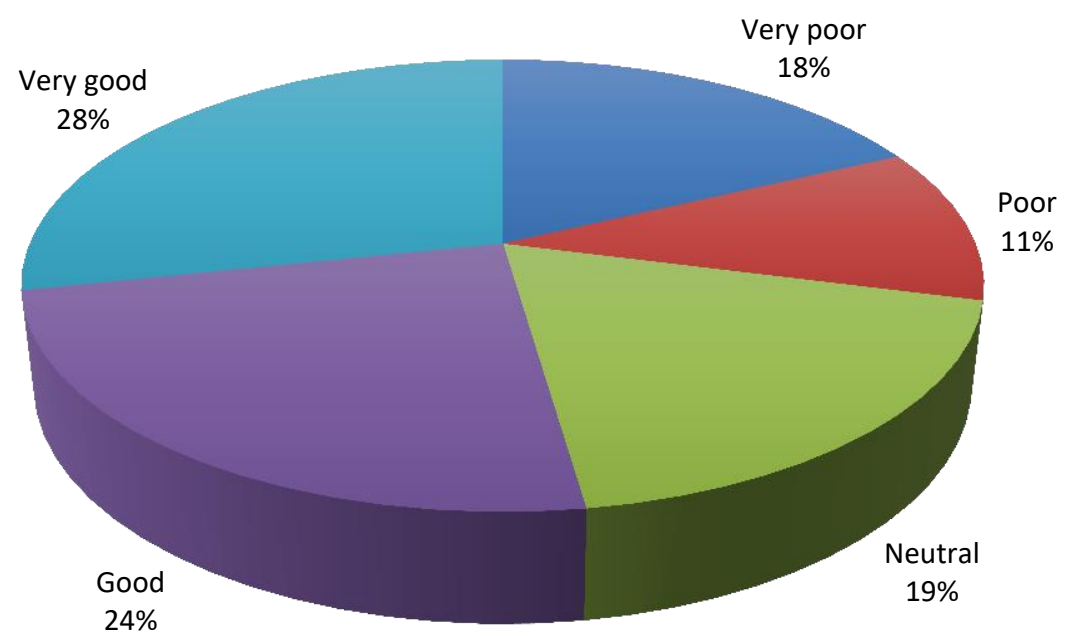

Figure 2:-Overall HSR on health care services in the OPD 


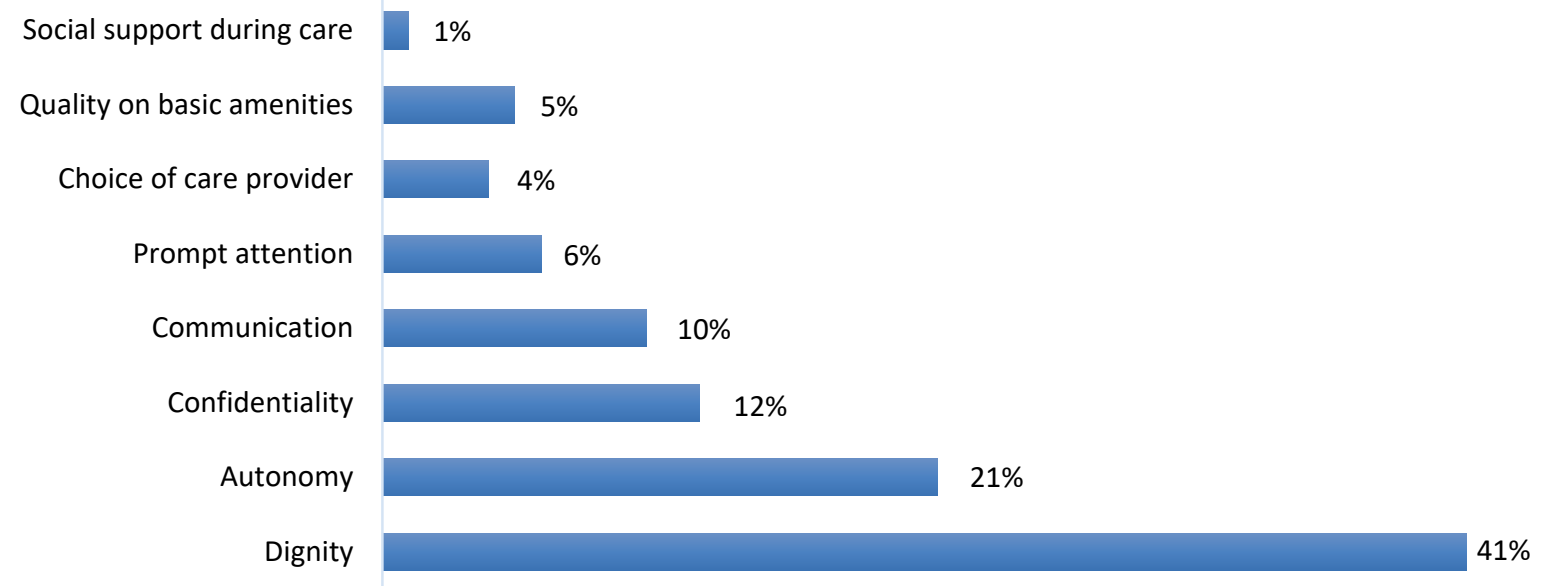

Figure 3:-Percentage of respondents ranking a responsiveness domain as the most important

Table 4:-Socio-demographic factors associated with overall HSR

\begin{tabular}{|c|c|c|c|c|}
\hline Characteristics & Less satisfactory (\%) & Neutral (\%) & Satisfactory (\%) & \\
\hline Gender & & & & $X^{2}=9.034$ \\
\hline Male & $42(32.3)$ & $33(25.4)$ & $55(42.3)$ & $\mathrm{df}=2$ \\
\hline Female & $73(27.4)$ & $41(15.4)$ & $152(57.2)$ & $\mathrm{p}=0.01$ \\
\hline \multicolumn{5}{|l|}{ Age (years) } \\
\hline $18-40$ & $21(20.8)$ & $11(10.9)$ & $69(68.3)$ & $X^{2}=26.15$ \\
\hline $41-60$ & $83(31.5)$ & $50(18.9)$ & $131(49.6)$ & $\mathrm{df}=4$ \\
\hline$>60$ & $11(35.5)$ & 13 (41.9) & $7(22.6)$ & $\mathrm{p}=0.000$ \\
\hline \multicolumn{5}{|l|}{$\begin{array}{l}\text { The highest educational } \\
\text { level }\end{array}$} \\
\hline Secondary level or below & $79(27.2)$ & 58 (19.9) & $154(52.9)$ & $X^{2}=2.351$ \\
\hline Above GCE (O/L) & $36(34.3)$ & $16(15.2)$ & $53(50.5)$ & $\begin{array}{r}\mathrm{df}=2 \\
\mathrm{p}=0.31\end{array}$ \\
\hline \multicolumn{5}{|l|}{$\begin{array}{l}\text { Current employment } \\
\text { status }\end{array}$} \\
\hline Unemployed & $35(18.5)$ & $35(18.5)$ & $119(63.0)$ & $X^{2}=21.694$ \\
\hline Employed & $80(38.6)$ & $39(18.9)$ & $88(42.5)$ & $\begin{array}{r}\mathrm{df}=2 \\
\mathrm{p}=0.000\end{array}$ \\
\hline \multicolumn{5}{|l|}{ Monthly income } \\
\hline Less than Rs. 25,000 & $105(37.6)$ & $69(24.8)$ & $105(37.6)$ & $X^{2}=81.18$ \\
\hline More than Rs. 25,000 & $10(8.5)$ & $5(4.3)$ & $102(87.2)$ & $\begin{array}{r}\mathrm{df}=2 \\
\mathrm{p}=0.000\end{array}$ \\
\hline
\end{tabular}

\section{References}

1 Arokiasamy, P., Guruswamy, M., Roy, T.K., Lhungdim, H., Chatterji, S., Nandraj, S., (2006), Health system performance assessment-World Health Survey 2003, India.

2 Bramesfeld, A., Klippel, U., Seidel, G., Schwartz, F.W., Dierks, M.L., (2007), How do patients expect the mental health service system to act? Testing the WHO responsiveness concept for its appropriateness in mental health care. Soc Sci \& Med. 65(5):880-9.

3 Bramesfeld, A., Wedegärtner, F., Elgeti, H., Bisson, S.,(2007), How does mental health care perform in respect to service users' expectations? Evaluating inpatient and outpatient care in Germany with the WHO responsiveness concept. BMC Health Serv Res. 7(1):99. 
4 Brinkerhoff, D.W. and Bossert, T.J., (2013). Health governance: principal-agent linkages and health system strengthening. Health Policy Plann, 29(6), pp.685-693.

5 Cleary, S.M., Molyneux, S. and Gilson, L., (2013), Resources, attitudes and culture: an understanding of the factors that influence the functioning of accountability mechanisms in primary health care settings. BMC health serv res, 13(1), p.320.

6 Jang, Y., Kim, G., Chiriboga D.A., (2005), Health, healthcare utilization, and satisfaction with service: Barriers and facilitators for older Korean Americans. Journal of the American Geriatrics Society; 53(9):1613-7.

7 Kalubowila, K.C., Perera, D., Senathilaka, I., Alahapperuma, C., Withana, R.D., Kapparage, P.D., (2017), Patient satisfaction of services at the out-patient department of Base Hospital Panadura, Sri Lanka, J. Coll. Comm. Phy. 23:2

8 Koggalage, P.D., Samarage, S., Sandanayake, A.P., Ranasinghe, G.S.P., Marantota, C., (2016), Patient satisfaction with services provided by service providers at the out-patient department in Base Hospital, Homagama. 24 ${ }^{\text {th }}$ Annual Academic Sessions of the College of Medical Administrators of Sri Lanka.

9 Kowal, P., Naidoo, N., Williams, S.R. and Chatterji, S., (2011), Performance of the health system in China and Asia as measured by responsiveness. Health, 3(10), p.638.

10 Liabsuetrakul, T., Petmanee, P., Sanguanchua, S. and Oumudee, N., (2012), Health system responsiveness for delivery care in Southern Thailand. Int J Qual Health C, 24(2), pp.169-175.

11 Lwanga S.K., Lemeshow S., (1991), Sample size determination in health studies: a practical manual. Geneva: World Health Organization.

12 Ministry of Health, (2008), Progress Report, Ministry of Health, Sri Lanka. Available at: http://www.health.gov.lk/enWeb/. Accessed on $16^{\text {th }}$ June 2019.

13 Ministry of Health, Nutrition and Indigenous Medicine, (2018), Available at: http://www.health.gov.lk/moh_final/english/g_hospital.php?id=60. Accessed on 16th June 2018.

14 Mosadeghrad, A.M., (2014), Factors influencing healthcare service quality. Int J health pol and ma, 3(2), p.77.

15 Peltzer, K., (2009), Patient experiences and health system responsiveness in South Africa. BMC Health Serv Res; 9(1):117.

16 Sajjadi, F., Moradi-Lakeh, M., Nojomi, M., Baradaran, H.R. and Azizi, F., (2015), Health system responsiveness for outpatient care in people with diabetes Mellitus in Tehran. Med. j. Islam. Repub. Iran, 29, p.293.

17 Siddiqi, S., Masud, T.I., Nishtar, S., Peters, D.H., Sabri, B., Bile, K.M. and Jama, M.A., (2009), Framework for assessing governance of the health system in developing countries: gateway to good governance. Health policy, 90(1), pp.13-25.

18 Valentine, N.B., De Silva, A., Kawabata, K., Darby, C., Murray, C.J., Evans, D.B., (2003), Health system responsiveness: concepts, domains and operationalization. Health systems performance assessment: debates, methods and empiricism. Geneva: World Health Organization: 573-96.

19 Valentine, N.B., de Silva, A., Kawabata, K., Darby, C., Murray, C.J. and Evans, D.B., (2003), Health system responsiveness: concepts, domains and operationalization. Health systems performance assessment: debates, methods and empiricism. Geneva: World Health Organization, pp.573-96.

20 World Health Organization, (2000), The world Health Report. Health systems: improving performance. Geneva: World Health Organization.

21 World Health Organization, (2001), Background paper for the technical consultation on Responsiveness concepts and measurement. Geneva: World Health Organization.

22 World Health Organization, (2018), Health services development. The WHO Health Systems framework. Available at: http://www.wpro.who.int/health_services/health_systems_framework/en/. Accessed on $16^{\text {th }}$ June 2018. 